\title{
Effect of night and day on preterm infants in a newborn nursery: randomised trial
}

\author{
N P MANN, R HADDOW, L STOKES, S GOODLEY, N RUTTER
}

\begin{abstract}
The effect of alternating night and day on sleep, feeding, and weight gain in 41 healthy preterm infants was examined in a randomised controlled trial. Twenty infants from a night and day nursery, where the intensity of light and noise was reduced between $7 \mathrm{pm}$ and $7 \mathrm{am}$, spent longer sleeping and less time feeding and gained more weight than 21 infants from a control nursery, where the intensity of light and noise was not reduced. Differences were significant and became apparent only after discharge home; they were still present three months after the expected date of delivery, when infants from the night and day nursery were an average of $0.5 \mathrm{~kg}$ heavier $(p<0.02)$.

These findings suggest that physical environment has an effect (either direct or indirect) on the subsequent behaviour of preterm infants and that exposure to night and day is beneficial.
\end{abstract}

\section{Introduction}

It is our impression that sleep problems are more common in infants born prematurely than in infants born at full term. Some parents of preterm infants think that poor nocturnal sleeping is caused by admission to a neonatal unit and in particular by the infant being exposed to constant light and noise. For example, a few parents find that the only way they can get their baby to sleep at night is to switch on the bedroom light and play music, mimicking the environment that the baby was exposed to in hospital.

In the neonatal unit of this hospital preterm infants are nursed in an intensive care ward until they no longer require close observation

\footnotetext{
Department of Neonatal Medicine and Surgery, City Hospital, Nottingham NG5 1PB

N P MANN, MD, MRCP, senior registrar in neonatal paediatrics

R HADDOW, NNB, nursery nurse

L STOKES, SEN, enrolled nurse

S GOODLEY, SRN, family care sister

N RUTTER, MD, MRCP, senior lecturer in child health

Correspondence to: Dr Rutter.
}

and are able to tolerate full enteral feeding. They are then transferred to one of two adjacent newborn nurseries, where oral feeding is established, and they are prepared for discharge home. It is the usual practice for the lights in these nurseries to be left permanently on, and no attempt is made to reduce the intensity of the light or noise at night. We therefore devised a study to see whether exposure to a cyclical day and night environment before discharge would influence the subsequent behaviour of preterm infants.

\section{Patients and methods}

The study was conducted from August to December 1984. Forty one healthy infants who were born after less than 36 weeks' gestation but no longer required intensive care or close observation were randomly assigned to one of the two nurseries, 21 to the control nursery and 20 to the night and day nursery. Infants above and below 30 weeks' gestation were separately assigned to achieve an even distribution between the nurseries. None had had a major neurological illness. The mean birth weight was 1.63 (range 1.02 to 2.43$) \mathrm{kg}$, and mean gestation was 31.8 (27 to 35 ) weeks. The age of the infants on entry to the study ranged from 1 to 63 days old; 10 were aged $\leqslant 7$ days, 21 were aged 8 to 21 days, and 10 were aged $>21$ days.

The control nursery contained six cots, measured $23 \times 13$ feet, had a large exterior window and smaller internal windows without curtains, and was lit by bright fluorescent strip lights that remained permanently on. No attempt was made to reduce noise from the radio, staff, parents, or other visitors at any time. The night and day nursery was identical in size and the number and distribution of windows. During the daytime the environment was identical in the two nurseries, but at $7 \mathrm{pm}$ the windows in the night and day nursery were covered by dark, lined curtains, the lights were turned out, and the only illumination was provided by a low intensity night light. The radio was turned off, and staff and visitors were urged to make as little noise as possible. Low light and noise intensity was then maintained until $7 \mathrm{am}$.

The infants spent at least 10 days in one of the two nurseries. The time (in hours) spent by each infant asleep, awake, or feeding was recorded over 48 hours at the following defined times: immediately before discharge home, at the expected date of delivery, and at six and 12 weeks after the expected date of delivery. Observations were recorded by shading in two successive 24 hour charts divided into individual hours. The observations before discharge were made by the nursing staff responsible for the infant in the nursery, and the mother was instructed in the method of recording at the same time. Subsequent observations were made by the mother at home, helped by home visits from one of three nurses (RH, LS, and SG). The 
infant was weighed on each occasion. The average time spent asleep, awake, or feeding in 24 hours was calculated from the 48 hours of observation.

Infants were studied with the informed consent of their parents, and the study was approved by the hospital's ethical committee. Data were recorded and analysed on an ICL 2900 computer with the statistical package for the social sciences. Results are expressed as means and SEM. Statistical comparisons were made with Student's unpaired $t$ test, the $\chi^{2}$ test, and analysis of covariance.

\section{Results}

Light and sound intensities were measured in the two nurseries on a randomly chosen day in the middle of the study without warning. Light intensity in the control nursery was about 200 lumen/ $\mathrm{m}^{2}$ throughout 24 hours, with no nocturnal decrease. Intensity in the night and day nursery decreased to 1 lumen $/ \mathrm{m}^{2}$ at $7 \mathrm{pm}$ and remained low until $7 \mathrm{am}$, when it increased to control intensity. Background sound intensity in the night and day nursery was about $10 \mathrm{~dB}$ lower than in the control nursery from $7 \mathrm{pm}$ to $7 \mathrm{am}$, and peaks of sound were of lower intensity and less frequent. Sound intensities in the two nurseries were similar during the day.

Comparison of the two groups of infants on admission to the study showed no significant differences in gestation, birth weight, or the amount of intensive care they had received (as judged by the length of time the infant had needed mechanical ventilation, oxygen, or total parenteral nutrition) (table I). The weights and ages of the infants on admission to the study did not differ significantly. Infants spent 10 to 42 (mean 19.3) days in their nursery before discharge, with no difference between the two groups. Comparison of the families of the infants showed no significant differences between the groups in maternal age, marital state, number of siblings, previous perinatal loss, social class, or the number of recent housing changes (table II). Most infants were fed on formula milks, and the prevalence of breast feeding was similar in the two groups.

TABLE I-Details of infants and their treatment, expressed as mean $(S D)$ (range)

\begin{tabular}{|c|c|c|c|}
\hline & $\begin{array}{c}\text { Infants in control } \\
\text { nursery }(n=21)\end{array}$ & $\begin{array}{l}\text { Infants in night and day } \\
\text { nursery }(n=20)\end{array}$ & Significance \\
\hline Gestation (weeks) & $31.6(1.9)(27-35)$ & $32 \cdot 0(2 \cdot 0)(28-35)$ & NS \\
\hline Birth weight $(\mathrm{kg})$ & $1.64(0.39)(1.02-2.43)$ & $1.62(0.35)(1.13-2.37)$ & NS \\
\hline Duration of oxygen & & & \\
\hline $\begin{array}{l}\text { treatment (days) } \\
\text { Duration of mechanical }\end{array}$ & $1 \cdot 3(2 \cdot 7)(0-9)$ & $4.9(10 \cdot 7)(0-48)$ & NS \\
\hline $\begin{array}{l}\text { Duration of mechanical } \\
\text { ventilation (days) }\end{array}$ & $0.6(1 \cdot 2)(0-5)$ & $0.8(1.8)(0-7)$ & NS \\
\hline $\begin{array}{l}\text { Duration of parenteral } \\
\text { nutrition (days) }\end{array}$ & $2 \cdot 1(3 \cdot 0)(0-9)$ & $3.9(10.5)(0-46)$ & NS \\
\hline $\begin{array}{l}\text { Age at entry to study } \\
\text { (days) } \\
\text { Length of time }\end{array}$ & $15 \cdot 8(13.6)(1-57)$ & $17 \cdot 6(13 \cdot 9)(5-63)$ & NS \\
\hline $\begin{array}{l}\text { participating in study } \\
\text { (days) }\end{array}$ & $19 \cdot 1(7 \cdot 5)(12-30)$ & $19 \cdot 5(6 \cdot 6)(14-47)$ & NS \\
\hline
\end{tabular}

^Compared with Student's $t$ test.

Infants from the night and day nursery spent less time awake than control infants, a significant difference that became apparent only after discharge from hospital (fig 1). After discharge they spent an average of two hours more in 24 hours asleep. This extra sleep was evenly distributed over 24 hours and was not solely nocturnal-both groups showed proportionately less sleep by day and more sleep by night with increasing age (table III). Infants from the night and day nursery spent an average of one hour less each day feeding, again a significant difference that became apparent after discharge (fig 2). In spite of this these infants showed a significantly greater weight gain than controls after discharge (fig 3), so that by three months after the expected date of delivery they were an average of $0.5 \mathrm{~kg}$ heavier.

\section{Discussion}

Why should infants nursed under conditions of alternating night and day sleep longer, spend less time feeding, and gain more weight than those nursed in perpetual light and noise? Furthermore, why should these differences become apparent only after discharge from hospital and still be present three months after the expected date of delivery? There are several possible explanations.

Firstly, the two groups of infants might be inherently different. This seems unlikely, as they were so similar at birth, in the amount and type of intensive care they had received, and on entry to the study. Alternatively, the families, especially the mothers, of infant 3 exposed to night and day might have been inherently more effective at rearing babies. This would explain the appearance of the differences between the groups after discharge, but we were unable to show any differences in the mothers and their families from

TABLE II-Details of the families of infants, expressed as mean (SD) (range)

\begin{tabular}{|c|c|c|c|}
\hline & $\begin{array}{l}\text { Infants in control } \\
\text { nursery }(n=21)\end{array}$ & $\begin{array}{c}\text { Infants in night and day } \\
\text { nursery }(n=20)\end{array}$ & Significance \\
\hline Maternal age (years) & $26 \cdot 2(5 \cdot 9)(19-40)$ & $23 \cdot 7(4 \cdot 4)(21-28)$ & $\mathrm{NS}^{\star}$ \\
\hline No of siblings & $0.9(1.5)(0-6)$ & $0.8(1.0)(0-3)$ & $\mathrm{NS}^{\star}$ \\
\hline \multirow{4}{*}{$\begin{array}{l}\text { No of changes of housing } \\
\text { in previous two years } \\
\text { No of married mothers } \\
\text { No of mothers in social } \\
\text { classes IV and V }\end{array}$} & $0.5(0.6)(0,3)$ & $0.2(0.4)(0,2)$ & \\
\hline & 15 & 14 & NSt \\
\hline & & & \\
\hline & 14 & 12 & NSt \\
\hline
\end{tabular}

^ Compared with Student's $t$ test. + Compared with $\chi^{2}$ test.

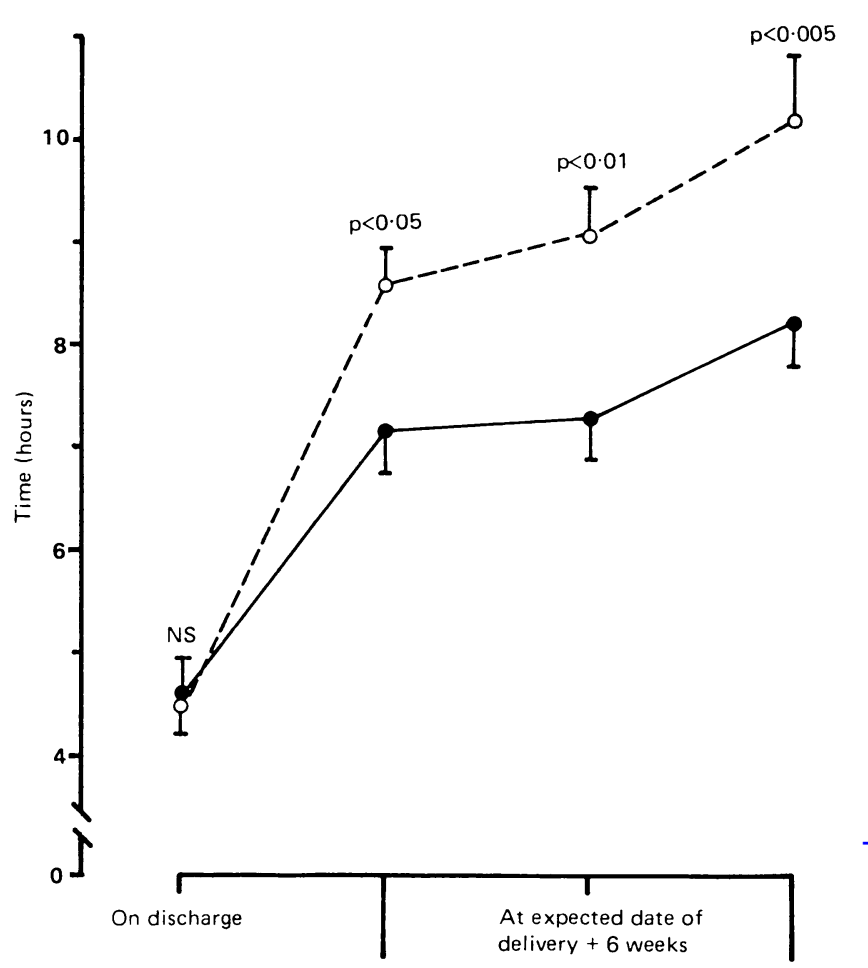

At expected date of delivery

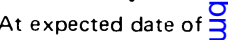
delivery +12 weeks

FIG 1-Mean number of hours spent awake in 24 hours in each group ( 0 -.. $0=3$ infants in control nursery; $\bullet-\bullet=$ infants in night and day nursery). Bar represent SE. Ditferences at each time point compared with Student's $t$ test Analysis of covariance shows an overall difference between groups with time $(\mathrm{p}<0 \cdot 001)$.

several family and social parameters. Feeding practices werew similar.

Secondly, exposure of the infants to a cyclical night and dayo environment could directly affect sleep, feeding, and weight gain There is evidence that an endogenous circadian rhythm of sleep ${ }^{\circ}$ develops spontaneously in the human infant but that alternating light and darkness hastens its appearance and synchronises it to night and day. ${ }^{\prime}$ The newborn infant born at full term sleeps equally by night and day, spending 16 to 17 hours in 24 asleep. ${ }^{2}$ By the age of 3 to 6 weeks the total time spent asleep has decreased to 14 to 150 hours, and the normal circadian pattern of more nocturnal and less diurnal sleep has appeared. This sequence is correspondinglyo delayed in preterm infants. ${ }^{34}$ Thus differences in sleep patterng 
between infants from the two groups would not be expected at birth but would appear after the expected date of delivery. Although infants from the night and day nursery spent two hours more asleep in 24 hours, however, this extra sleep was evenly distributed, and there was no earlier development of a circadian sleep pattern compared with control infants (table III). Nevertheless, sleep, appetite, and weight gain are all under the influence of the hypothalamus and could therefore be affected by exposure to night and day. Alternatively, if only sleep was influenced by the cyclical environment, weight gain could increase as a secondary phenomenon due to the anabolic effect of sleep.

TABLE III-Sleep distribution over 24 hours in the two groups of infants (figures are numbers of hours of sleep)

\begin{tabular}{|c|c|c|c|c|}
\hline & \multicolumn{2}{|c|}{ Day (7 am-7 pm) } & \multicolumn{2}{|c|}{ Night (7 pm-7 am) } \\
\hline & $\begin{array}{l}\text { Infants in } \\
\text { control } \\
\text { nursery }\end{array}$ & $\begin{array}{l}\text { Infants in } \\
\text { night and day } \\
\text { nursery }\end{array}$ & $\begin{array}{l}\text { Infants in } \\
\text { control } \\
\text { nursery }\end{array}$ & $\begin{array}{l}\text { Infants in } \\
\text { night and day } \\
\text { nursery }\end{array}$ \\
\hline \multirow{4}{*}{$\begin{array}{l}\text { On discharge } \\
\text { At expected date of delivery } \\
\text { At expected date of delivery }+ \\
\text { six weeks } \\
\text { At expected date of delivery+ } \\
12 \text { weeks }\end{array}$} & $9 \cdot 7$ & $9 \cdot 5$ & 9.9 & $10 \cdot 0$ \\
\hline & $7 \cdot 5$ & 8.0 & $8 \cdot 0$ & 9.0 \\
\hline & 6.8 & 8.0 & $8 \cdot 4$ & $9 \cdot 0$ \\
\hline & & & 8.6 & \\
\hline
\end{tabular}

Finally, exposure of infants to night and day could possibly affect them less directly. For example, the mothers may have had more confidence in the health and wellbeing of their infants, as the medical and nursing staff seemed happy to leave them alone in a quiet, darkened room for long periods. This might have led to more confidence and less anxiety in their management at home, with the result that the infants slept longer, fed well, and gained weight more

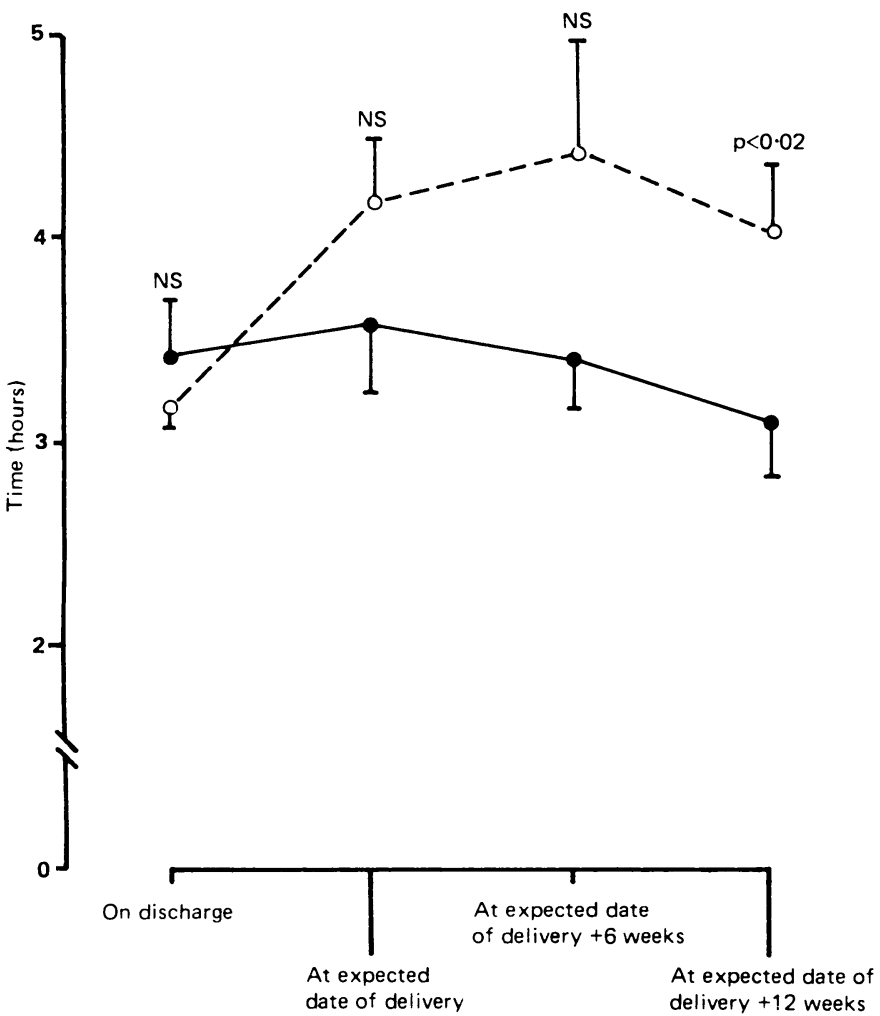

FIG 2-Mean number of hours spent feeding in 24 hours in each group ( 0 -.- $0=$ infants in control nursery; $\bullet-\bullet=$ infants in night and day nursery). Bars represent SE. Differences at each time point compared with Student's $t$ test. Analysis of covariance shows an overall difference between groups with time $(\mathrm{p}<0.05)$.

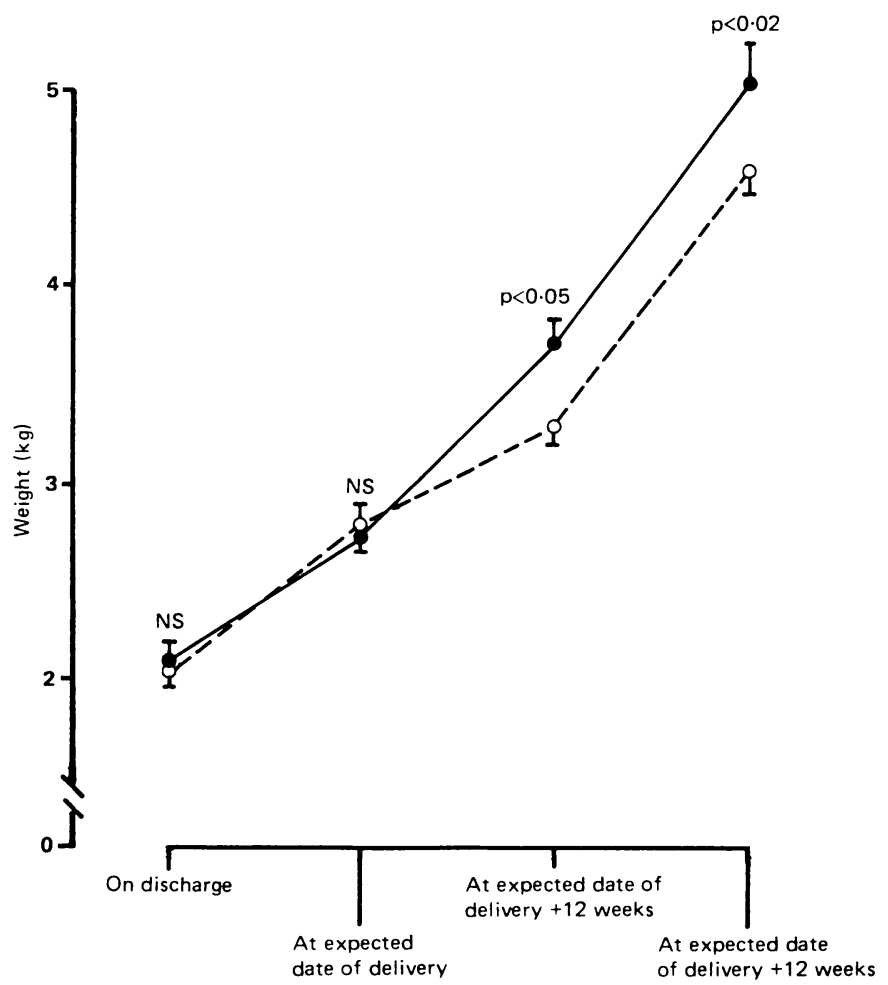

FIG 3-Mean weights of babies in the two groups $(0---\circ=$ infants in control nursery; $\bullet-1-$ infants in night and day nursery). Bars represent SE. Differences at each time point compared with Student's $t$ test. Analysis of covariance shows an overall difference between groups with time $(p<0.005)$.

quickly. Certainly, excessive handling of young infants disrupts their sleep patterns. ${ }^{6}$ Although the two groups were subjected to different environments in hospital, we do not know whether they were subjected to different intensities of light and noise once they had been discharged home.

Whatever the explanation the differences are real and appreciable. Assuming that it is beneficial for a young infant to sleep longer, spend less time feeding, and gain weight quickly, we recommend that preterm infants in nurseries for the newborn are not subjected to constant light and noise. It is the control infants in this study who seem to be receiving a "treatment" with an adverse effect. Our use of constant light and noise has slowly evolved from the wish to provide a neonatal unit with an environment that is less stressful and more relaxing to the parents and staff. The results of this study suggest that it is not in the best long term interests of the infants or their parents.

We thank the medical and nursing staff of the neonatal unit for their cooperation in this study, in particular Mrs Paula Hale, divisional nurse manager of neonatal services. We are grateful to Dr Sue Mann, who computerised the data, and Mr Paddy Riley, who advised on the statistical analysis. Finally, we thank Miss Ros Richardson of medical physics for helping with measuring light and sound.

\section{References}

1 Martin-du-Pan R. Le rôle du rythme circadian dans l'alimentation du nourrisson. La femme e l'enfant 1970;4:23-30.

2 Hellbrugge T. The development of circadian rhythms in infants. Cold Spring Harbor Symp Quant Biol 1960;25:311-23.

3 Hellbrugge T. The development of circadian and ultradian rhythms of premature and full term infants. In: Schevring LS, Halberg F, Pauly JE, eds. Chronobiology. Tokyo: Igaku Shoin, 1974:339-41.

4 Minors DS, Waterhouse JM. Development of circadian rhythms in infancy. In: Davies JA, Dobbing J, eds. Scientific foundations of paediatrics. 2nd ed. London: Heinemann, 1981: 980-97. 5 Fagioli I, Ricour C, Salomon F, Salzarulo P. Weight changes and sleep organisation in infants. Eary Hum Dev 1981:5:395-9.

6 Gabriel M, Grote B, Jonas M. Sleep-wake pattern in preterm infants under two different care schedules during four-day polygraphic recording. Neuropediatrics 1981;12:366-73.

(Accepted 28 August 1986) 